\title{
Mountain Torques and Northern Hemisphere Low-Frequency Variability. Part II: Regional Aspects
}

\author{
FRANÇOIS LOTT \\ Laboratoire de Météorologie Dynamique, IPSL, Ecole Normale Supérieure, Paris, France \\ ANDREW W. Robertson ${ }^{*}$ AND Michael GHIL ${ }^{+}$ \\ Department of Atmospheric Sciences, and Institute of Geophysics and Planetary Physics, University of California, Los Angeles, \\ Los Angeles, California
}

(Manuscript received 16 November 2001, in final form 20 November 2003)

ABSTRACT

\begin{abstract}
Important aspects of low-frequency variability (LFV) are regional in character, while the mountain torques of the Rockies and the Himalayas evolve quite independently of each other. The hemispheric analysis of Part I is complemented therefore herein by an analysis of the relationships between individual mountain torques and sectorial LFV patterns in the NCEP-NCAR reanalysis.

In the 20-30-day band, relationships are found between the Rockies (Himalayas) torque and the dominant patterns of LFV over the Pacific (Eurasia). The composites of the atmospheric flow fields that accompany the Rockies (Himalayas) torque in this band exhibit similarities with known low-frequency oscillations that dominate the Pacific and North American (European and North Atlantic) sectors during certain winters. The composites keyed to the 20-30-day Rockies torque affect the persistent North Pacific (PNP) pattern that controls the extension of the midlatitude jet stream over the eastern Pacific. Furthermore, the unfiltered torques for the Northern Hemisphere $(\mathrm{NH})$ and Rockies anticipate the onset of the two dominant winter Pacific circulation regimes that correlate strongly with the PNP pattern. The composites keyed to the 20-30-day Himalayas torque affect the North Atlantic Oscillation (NAO) pattern, which controls the intensity of the North Atlantic jet stream. Furthermore, the unfiltered torques for the $\mathrm{NH}$ and the Himalayas anticipate the breaks of the two dominant winter Atlantic circulation regimes, which correlate strongly with the NAO pattern.

These analyses also show that the 20-30-day Rockies (Himalayas) torques produce substantial atmospheric angular momentum (AAM) changes, which are nearly in phase with and larger in amplitude than the AAM changes associated with the midlatitude eastern Pacific (North Atlantic) jet stream variations seen in the composite maps. This result suggests that the Rockies (Himalayas) torque variations drive, at least partially, but actively the changes in the eastern Pacific (North Atlantic) jet stream.

These results are consistent with the Himalayas and the Rockies torques contributing separately to changes in the two leading hemispheric EOFs that were described in Part I; the two are associated with a hemispheric index cycle and the Arctic Oscillation, respectively.
\end{abstract}

\section{Introduction and motivation}

In Part I (Lott et al. 2004) of this study we have shown that the atmospheric circulation patterns associated with the Northern Hemisphere $(\mathrm{NH})$ mountain torque $\left(T_{M}\right)$ in the 20-30-day band have large amplitudes in well-

\footnotetext{
* Current affiliation: International Research Institute for Climate Prediction, Palisades, New York.

+ Additional affiliation: Département Terre-Atmosphère-Océan and Laboratoire de Météorologie Dynamique, Ecole Normale Supérieure, Paris, France.
}

Corresponding author address: François Lott, Laboratoire de Météorologie Dynamique, Ecole Normale Supérieure, 24 rue Lhomond, 75235 Paris Cédex 05, France.

E-mail: flott@1md.ens.fr defined geographical areas of the Pacific-North American and North Atlantic-European sectors, located far from the major mountain ranges. These localized patterns suggest that mountain torques and low-frequency variability (LFV) may be related on a regional scale as well. A regional approach is also justified by numerous observational (Wallace and Gutzler 1981; Penland et al. 1991; Cheng and Wallace 1993; Kimoto and Ghil 1993b; Plaut and Vautard 1994; Smyth et al. 1999) and model (Ghil et al. 1991b; Marcus et al. 1996) studies, which have shown that LFV is often regional in character.

Relationships between regional mountain torques and sectorial LFV, although not previously identified, can be expected for various reasons. In Part I, for instance, the signal in $700-\mathrm{hPa}$ geopotential heights $\left(Z_{700}\right)$ that is 
related to the 20-30-day NH mountain torque propagates westward over the Pacific, suggesting that it is associated with the traveling low-frequency oscillations that dominate Pacific LFV during certain winters (Branstator 1987; Kushnir 1987). Other sectorial LFV patterns can generate regional mountain torques because they are strongly nonzonal and located near the dominant NH mountain ranges. They can thus induce pressure differences in the zonal direction across these ridges and therewith a mountain torque. Conversely, mountains can force Rossby lee waves that may explain blocking onset downstream of the major ridges (KalnayRivas and Merkine 1981). Through interactions between traveling low-frequency oscillations and the major mountain ranges, regional mountain torques can also provide part of the force needed to change the jet stream intensity in certain regional sectors.

Observational studies that emphasize the temporal characteristics of LFV have focused on persistent and quasi-stationary flow configurations, generally called persistent anomalies (Dole and Gordon 1983). The often intermittent nature of atmospheric LFV suggests that an alternative or complementary approach to the oscillatory description used in Part I of this paper (see also Dickey et al. 1991; Plaut and Vautard 1994; Marcus et al. 1996) is necessary (Ghil et al. 1991a; Ghil and Roberston 2002). This approach consists of 1) analyzing LFV in terms of flow regimes (Mo and Ghil 1987; Cheng and Wallace 1993; Kimoto and Ghil 1993a) and 2) describing the transitions between them (Ghil 1987; Vautard et al. 1990; Kimoto and Ghil 1993b; Koo et al. 2002).

The first purpose of this Part II of the study is to examine relationships between the two major NH mountain ranges (Rockies and Himalayas) and the major patterns of regional LFV in the 20-30-day band; the importance of this band for hemispheric relationships between LFV patterns and mountain torques was demonstrated in Part I. Second, we want to verify, using atmospheric angular momentum (AAM) budgets, whether the observations confirm that regional mountain torques play an active role in driving regional LFV patterns. Third, we want to determine to what extent, if any, the results in Part I have significant regional aspects. Fourth, we want to know if these relationships are substantial enough for the individual torques to be related with sectorial weather regimes.

We pursue the investigation of the statistical relationships between NH LFV and mountain torques made in Part I by carrying out a regional analysis of LFV and mountain torques. The dataset used for these purposes is, again, the National Centers for Environmental Prediction-National Center for Atmospheric Research (NCEP-NCAR) reanalysis dataset described in Part I. To reduce the length of the series and to focus on the intraseasonal (IS) 10-150-day band, we also proceed as in Part I (see beginning of section 2 there) and form two sets of series sampled every 3 days, the $3 \mathrm{~d}$ series and the IS series, respectively.

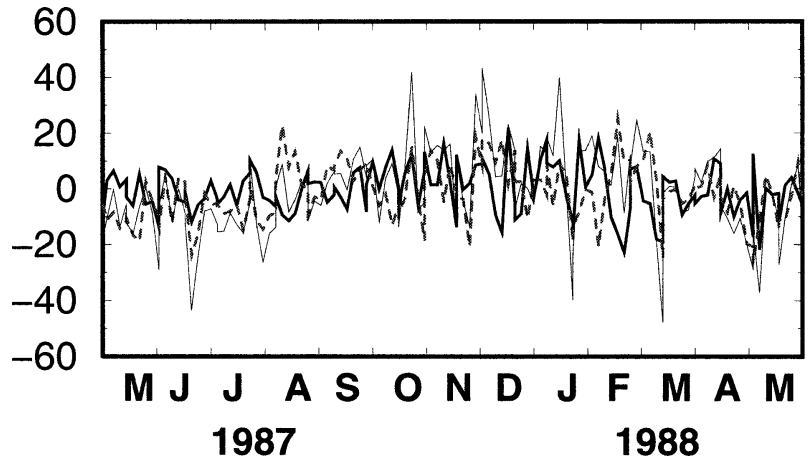

FIG. 1. Northern Hemisphere mountain torque (light solid) and mountain torques due to the Rockies (heavy solid) and the Himalayas (dashed).

In section 2, we study separately the regional torques and the sectorial patterns of NH LFV. In section 3, we analyze the relationships between the Rockies torque and the Pacific-North American variability. Section 4 deals with the relationships between the Himalayas torque and the variability over the Atlantic-European and Eurasian sectors. In section 5, we study sectorial LFV in terms of multiple circulation regimes and investigate the relationship, if any, between regional mountain torque anomalies and these regimes. The conclusions of Part II follow in section 6.

\section{Regional analysis: Torques and EOFs \\ a. Regional torques}

Figure 1 shows the $3 \mathrm{~d}$ series of the $\mathrm{NH}$ mountain torque $T_{M}$ and the individual contributions of the Rockies and Himalayas to that torque over the same 13-month interval as in Fig. 1 of Part I. The Rockies and Himalayas torque in Fig. 1 are evaluated using Eq. (7) in Part I, but with the sum limited to the domains $20^{\circ}-70^{\circ} \mathrm{N}, 160^{\circ}-$ $85^{\circ} \mathrm{W}$ and $20^{\circ}-35^{\circ} \mathrm{N}, 55^{\circ}-125^{\circ} \mathrm{E}$, respectively. The dominant contribution to the $\mathrm{NH}$ torque over the entire 40yr interval comes from the sum of the torques due to the Rockies and the Himalayas (not shown). The variance of the sum of these two torques represents $85 \%$ of the variance of the entire $\mathrm{NH}$ torque. The two regional torques have comparable amplitude, the variance of the Rockies torque being $75 \%$ of the Himalayas.

The Himalayas and Rockies torques evolve quite independently of each other: the correlation between the two is 0.1 for the $3 \mathrm{~d}$ series and 0.05 for the IS series. In January 1988, for instance, they reinforce each other to give a pronounced algebraic minimum, while in February 1988 the substantial minimum in the Rockies torque is largely compensated by the maximum in the Himalayas torque.

The atmospheric patterns associated with the IS mountain torque variations are shown in Fig. 2. They are obtained by regressing the $700-\mathrm{hPa}$ geopotential heights $\left(Z_{700}\right)$ with respect to each mountain torque over 


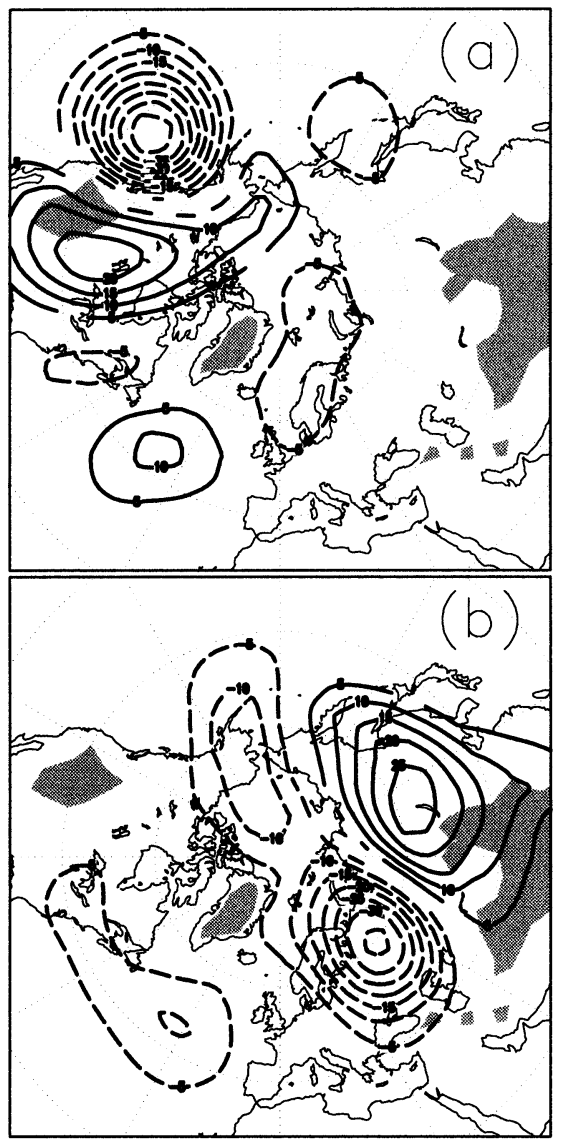

FIG. 2. Map of 700-hPa geopotential height field regression with respect to the mountain torque of the (a) Rockies and (b) Himalayas in the intraseasonal band; altitudes above $1500 \mathrm{~m}$ shaded. Positive contours are solid, negative ones are dashed; contour interval is 5 m. See Fig. 2 in Part I for the regression with respect to the total NH mountain torque.

the 40-yr interval, all data being filtered to retain the IS band. East-west dipole patterns span the Rockies and the Himalayas, respectively, with their nodal lines located on the western (upwind) flanks of either mountain range. The amplitudes of the patterns in Figs. 2a and $2 \mathrm{~b}$ are comparable, as expected from the fact that these two mountain ranges make comparable contributions to the NH mountain torque. The sum of the two dipoles essentially makes up the pattern constructed for the total NH $T_{M}$ (see Fig. 2 of Part I).

\section{b. Sectorial EOFs}

To address the regional aspects of NH LFV and the potential influence of the separate mountain ranges on them, we carry out sectorial analyses along the same lines as the hemispheric analysis of empirical orthogonal functions (EOFs) and torques presented in section 4 of Part I. The leading regional LFV patterns are determined by EOF analyses of the Pacific-North American sector $\left(120^{\circ} \mathrm{E}-60^{\circ} \mathrm{W}\right.$ : PAC $)$, the North Atlantic-European sec- tor $\left(90^{\circ} \mathrm{W}-90^{\circ} \mathrm{E}\right.$ : ATL $)$, and the Eurasian sector $\left(0^{\circ}-\right.$ $180^{\circ}$ : ASI).

To capture the dominant patterns of atmospheric variability, we compute the EOFs in each sector from 3day mean $700-\mathrm{hPa}$ geopotential maps over the 40-yr record. EOF-1 for each of these sectors (not shown) is essentially of one (arbitrary) sign and represents the regional counterpart of the hemispheric EOF-1. Each sectorial EOF-1 describes changes in the midlatitude jet intensity that are associated primarily with the seasonal cycle (see Fig. 7a in Part I).

Over the Atlantic and Pacific sectors, EOF-2 represents changes in intensity of the midlatitude jet stream, as captured by NH EOF-2 (Fig. 7b in Part I): ATL EOF2 (Fig. 3a) resembles the North Atlantic Oscillation (NAO) (van Loon and Rogers 1978), while PAC EOF2 (not shown) has features in common with the West Pacific Oscillation (WPO) during winter months (Barnston and Livezey 1987).

The third EOF in each sector (PAC in Fig. $3 b$ and ASI in Fig. 3c) is wave train-like, with the dominant centers lying over the primary regions of high LFV: the Gulf of Alaska for the PAC sector and northern Scandinavia for the ASI sector. PAC EOF-3 (Fig. 3b) exhibits an east-west dipole with its $\mathrm{N}-\mathrm{S}$ axis over the Canadian Rockies, while its strongest center of action is over the Gulf of Alaska. Its two opposite phases correspond to extension and contraction of the midlatitude jet over the eastern North Pacific; it is strongly reminiscent of Dole and Black's (1990) persistent North Pacific (PNP) pattern.

ASI EOF-3 (Fig. 3c) is an E-W dipole, having its strongest center of action over northern Scandinavia. It contains features of Wallace and Gutzler's (1981) eastern Atlantic pattern and of Barnston and Livezey's (1987) Eurasian pattern, type 1. It is quite similar to the ATL EOF-3 (not shown), indicating the robustness of their common feature, the center of action over northern Scandinavia.

\section{Rockies torque and regional LFV}

The cross-spectra between the Rockies torque and the leading PAC principal components (PCs) show significant peaks in the 20-30-day band. For instance, in this frequency band, the cross-spectrum between the Rockies torque and PAC PC-3 (Fig. 4a) exhibits highly significant peaks: the two series are essentially in phase with the torque slightly leading the changes in PC-3. This relationships follows from the fact that PAC EOF3 (Fig. 3b) is dominated by large geopotential height variations across the Rockies that clearly entail a mountain torque. Another strong peak in the cross-spectrum with PC-3 is also present at 50-60 days and is probably controlled by tropical oscillations, which do not concern us here.

Similar analyses indicate that in the 20-30-day band, the Rockies torque is in quadrature with the first PAC $\mathrm{PC}$ and almost in quadrature with the second PC (not 

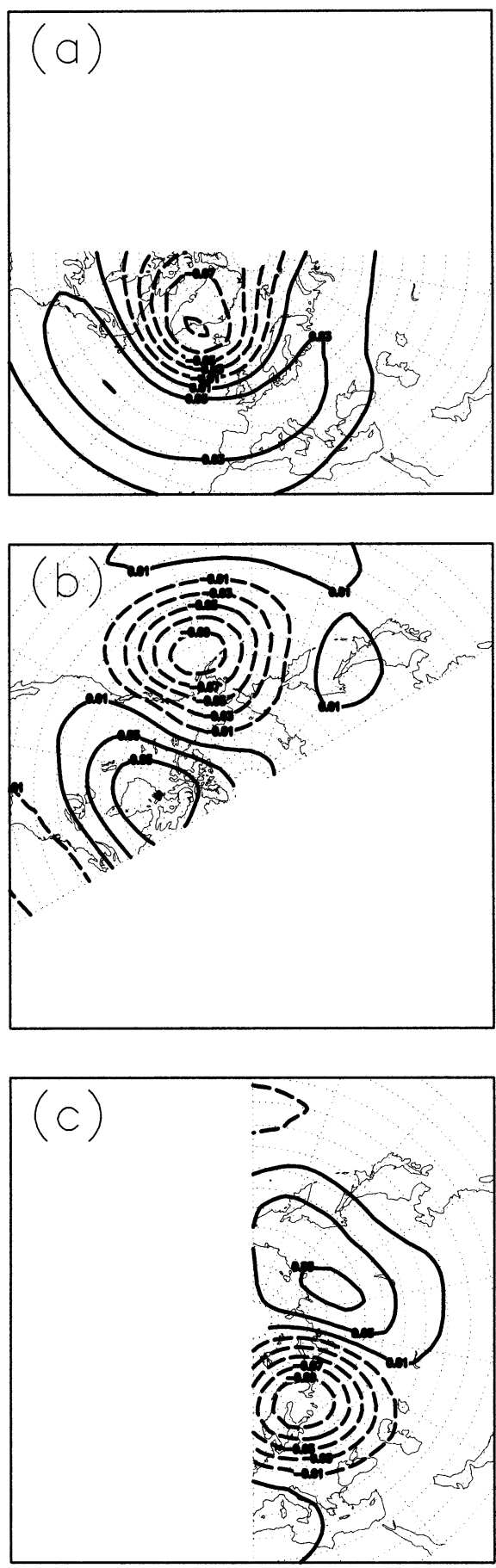

FIG. 3. Selected regional EOFs of the 700-hPa geopotential heights: (a) ATL EOF-2, (b) PAC EOF-3, and (c) ASI EOF-3.

shown). The latter relationship is quite modest in amplitude, and only one peak at 23-24 days is significant in the cross-spectrum at the $99 \%$ level. There is no strong correlation between the leading PCs (that is the PCs 1 to 3) over the ATL and ASI sectors and the Rockies torque.

To examine the lead-lag relationship between the
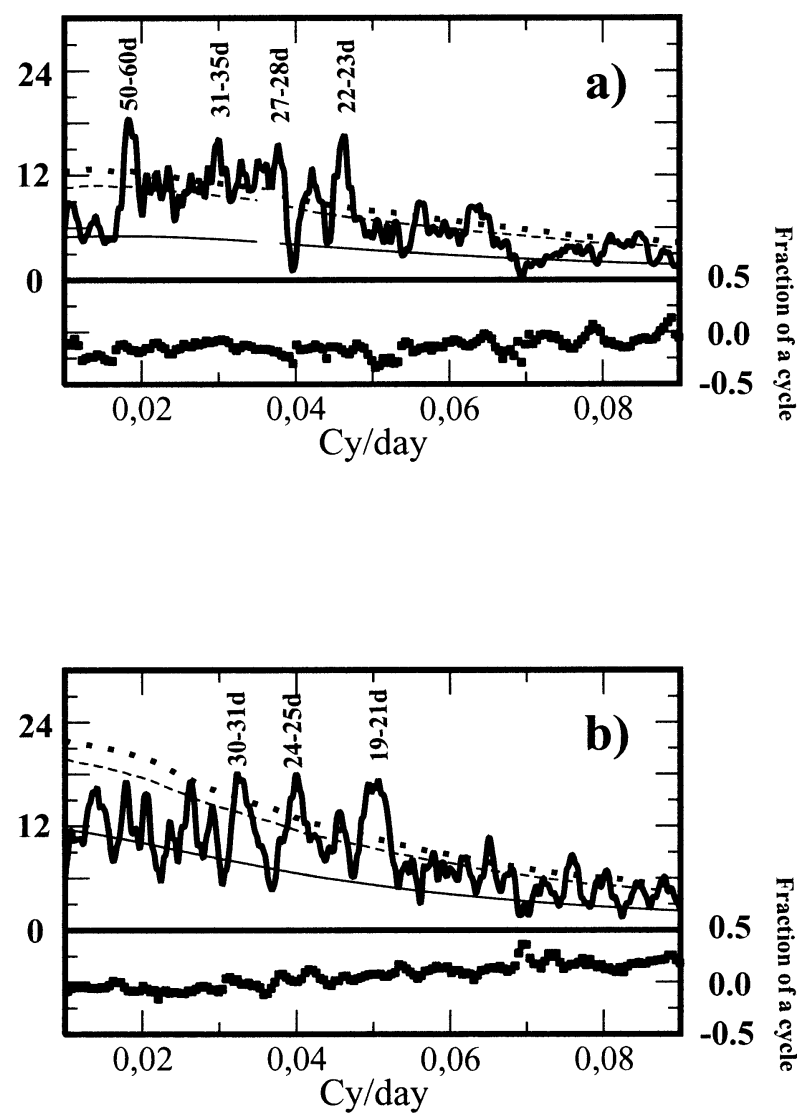

FIG. 4. Cross-spectra between regional torques and sectorial PCs: (a) Rockies $T_{M}$ vs PAC PC-3 and (b) Himalayas $T_{M}$ vs ASI PC-3. Same conventions, parameters, and methods as in Fig. 8 of Part I. Upper plots in (a) and (b): cross-spectral amplitude (thick solid) with 99\% confidence level (heavy dots), 95\% confidence level (light dashes), and median (light solid) of Monte Carlo test. Lower plot in (a) and (b): phase difference (filled squares).

Rockies torque and PAC PC-3 (Fig. 4a), we filter the Rockies $T_{M}$ series by using the 20-30-day bandpass filter introduced in section 3 of Part I. The bandpassed series represents about $40 \%$ of the IS variance of the Rockies torque. The corresponding IS $Z_{700}$ composites are shown in Fig. 5, which is computed in the same way as Fig. 5 of Part I, with a threshold value of 11.8 $\mathrm{H}$ for the 20-30-day Rockies $T_{M}$. With this value, $N_{c}$ $=80 \mathrm{IS} Z_{700}$ maps enter into each composite, the same number as used in the hemispheric Fig. 5. As in Part I, we have verified that our sectorial results here are not sensitive to moderate changes in the threshold.

At -3 day lag (Fig. 5a), the composite shows a strong SE-NW dipole with a pronounced cyclonic anomaly along the western flank of the Rockies and an anticyclonic one centered over the Alaskan peninsula. The successive positive and negative anomaly centers downstream of the Rockies are indicative of the presence of Rossby lee waves. At 0-day lag (Fig. 5b), which is in phase with the extrema of the Rockies torque, the cyclonic anomaly located along the western flank of the 


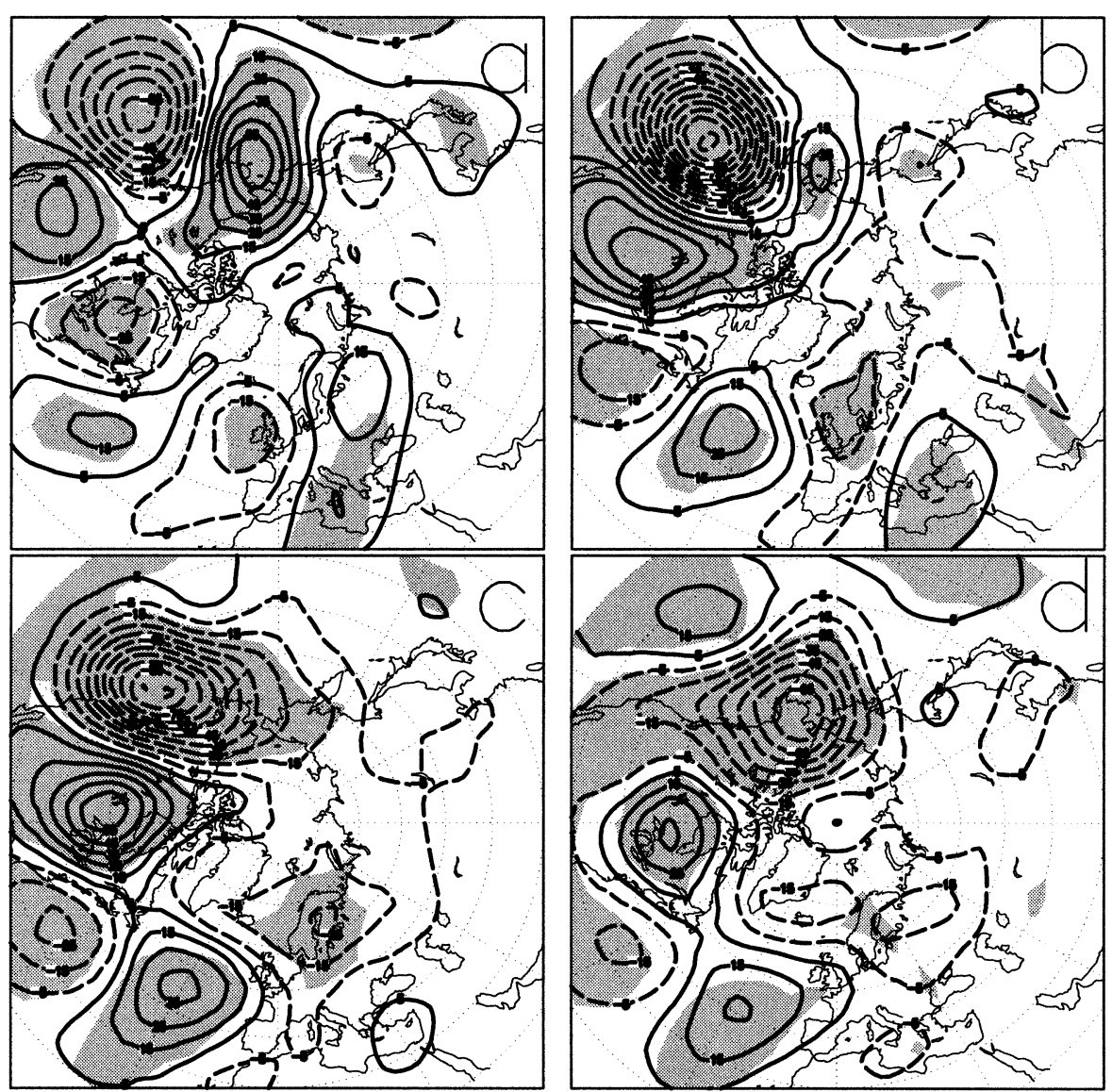

FIG. 5. Composite anomalies of $Z_{700}$ maps from the IS time series, keyed to the 20-30-day signal of the Rockies mountain torque: (a) -3 day lag, (b) 0-day lag, (c) 3-day lag, and (d) 6-day lag. Same procedure, conventions, and parameters as in Fig. 5 of Part I.

Rockies has increased in size and intensity and moved $5^{\circ}$ northward. By this time, the downstream wave train has increased in amplitude, while the anticyclonic anomaly over Alaska has weakened and contracted con-

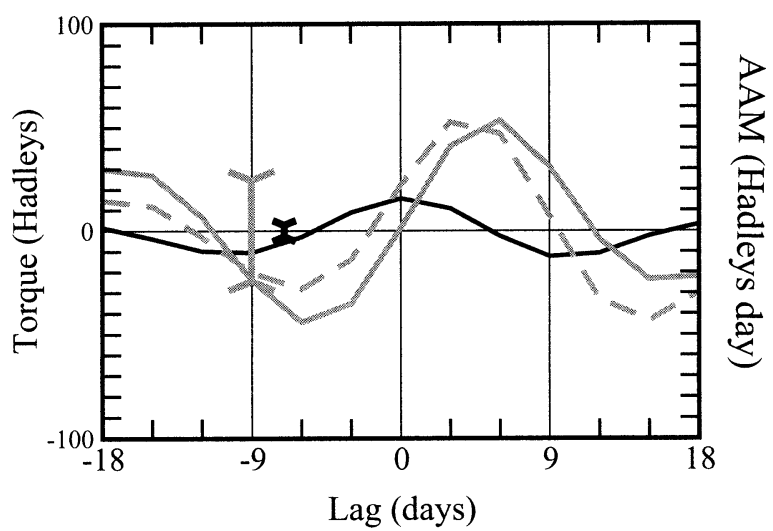

FIG. 6. Composites of different terms in the AAM budget during the composite cycle illustrated in Fig. 5: IS Rockies torque (black solid), integral of IS Rockies torque (gray solid), and global IS $M$ (gray dashed). Same conventions and parameters as in Fig. 6 of Part I. siderably; the composite essentially reproduces the dipole pattern associated with a strong Rockies torque in Fig. 2a. As time increases further, the cyclonic pattern located upstream of the Rockies starts to spread and move northwestward (Fig. 5c). It is at this time that the composite exhibits the largest correlation with PAC EOF-3 in Fig. 3b. The cyclonic pattern becomes centered near the Alaskan peninsula at 6-day lag, which is in approximate quadrature with the Rockies torque (Fig. $5 d)$.

The evolution of the AAM budget, as keyed to the to 20-30-day Rockies torque, is displayed in Fig. 6. At -3 day lag, the AAM (gray dashed line in Fig. 6) is near 0 . This indicates that the positive AAM associated with the southern flank of the cyclonic pattern located upstream of the Rockies in Fig. 5a is balanced by the negative AAM associated with the anticyclone centered over the northern Central Pacific. At 0-day lag, the cyclonic pattern amplifies, while the anticyclonic one decays, and the AAM becomes positive. Note that, because of earth's sphericity, cyclonic anomaly patterns in midlatitudes make a positive contribution to AAM, while the contribution of anticyclonic anomalies is negative. 
The composite AAM value at this time is near $25 \mathrm{H} \mathrm{d}$, which is moderate when compared to the AAM standard deviation of $100 \mathrm{H} \mathrm{d}$ in the IS band but still significant at the $95 \%$ level, as indicated by the thick gray vertical bar in Fig. 6. Thereafter, the AAM increases to reach a maximum above $50 \mathrm{H}$ d at 3-day lag, when the cyclonic anomaly has extended to cover most of the northeastern Pacific. At 6-day lag, the AAM starts to decay; at this time the cyclonic anomaly has contracted in space, decreased in amplitude, and moved substantially northward.

The Rockies torque composite in the IS band (black solid in Fig. 6) also reaches substantial values when compared for instance with the NH mountain torque's standard deviation of $\sigma_{T}=10 \mathrm{H}$ (see Part I). The integral of the IS Rockies torque (thick gray line in Fig. 6) agrees quite well in phase and amplitude with the IS AAM variations.

The curves in Fig. 6 are consistent with the Rockies torque contributing to the changes in the eastern Pacific subtropical and midlatitude jets seen in Fig. 5. To verify this consistency more quantitatively, we have evaluated the contribution to the AAM from the anomaly patterns in Fig. 5, by retaining in the horizontal AAM integrals in Eqs. (3) and (5) of Part I only the contribution of the eastern midlatitude Pacific $\left(20^{\circ}-50^{\circ} \mathrm{N}, 120^{\circ} \mathrm{W}-180^{\circ}\right)$. The evolution of the AAM evaluated over this sector and keyed to the 20-30-day Rockies torques (not shown) is almost exactly in phase with the composite evolution of the global IS AAM in Fig. 6, and about 3 times smaller in amplitude. This result remains valid if we take for the barotropic wind in Eq. (5) of Part I and, for the surface pressure $P_{s}$ in Eq. (6) of Part I, the values derived from the maps in Fig. 5 by using geostrophy and hydrostatic equilibrium, respectively. The Rockies torque is thus easily large enough to drive the flow pattern changes in the eastern Pacific between $20^{\circ}$ and $50^{\circ} \mathrm{N}$, shown in Fig. 5.

Two additional items deserve attention here. The first is the presence of Rossby lee waves in Fig. 5, which supports the theory of Kalnay-Rivas and Merkine (1981), who attributed blocking onset over the North Atlantic to such waves. Unfortunately, the low correlations between the Rockies torque and the ATL PCs indicate that the circulation anomalies associated with the Rockies over the Atlantic are too weak to correlate significantly with one of the leading Atlantic EOFs.

The second item is that, over the eastern Pacific, our coherent large-scale circulation patterns in Fig. 5 have some features in common with the 25-day oscillation found by Branstator (1987), Kushnir (1987), and Ghil and Mo (1991) using more direct methods. For instance, we note the northward and slightly westward displacement of the low that is located initially along the western flank of the Rockies in Fig. 5a and settles over the Alaskan peninsula 9 days later in Fig. 5d. This shift is reminiscent of the displacement of the low that starts off along the western flank of the Rockies in Fig. 11c of Kushnir (1987) and ends up slightly to the south of Alaska in Fig. 11e, 10 days later.

\section{Himalayas torque and regional LFV}

The cross-spectra between the Himalayas torque and the leading ASI PCs also show significant peaks in the 20-30-day band. Thus, the cross-spectrum between the Himalayas torque and ASI PC-3 exhibits a highly significant peak near 20 days and three other less pronounced peaks in this band (Fig. 4b). In this frequency band, the two series are almost in phase with PC-3 slightly leading the changes in the torque. The spatial pattern of ASI EOF-3 (Fig. 3c) shows that a positive $\mathrm{PC}-3$ is associated with a pronounced low over Scandinavia. A negative anomaly of similar extent is associated, at zero lag, with a large Himalayas torque (Fig. 2b).

In the same band, the Himalayas torque is in quadrature with the first ASI PC (not shown), which characterizes changes in the midlatitude jet's intensity near the subtropics and over the western Pacific. Highly significant relationships are also found for ASI PC-2 (not shown).

In this band, a correlation exists, furthermore, between the Himalayas torque and ATL PC-2, which captures the evolution of the NAO; the torque and the PC are in quadrature (not shown). It is consistent with the $\mathrm{NH}$ mountain torque and NH PC-2 being in quadrature (see Part I) because the Himalayas torque makes a substantial contribution to the NH torque and because ATL EOF-2 (the NAO) is the sectorial component of the $\mathrm{NH}$ EOF-2 (the Arctic Oscillation; see section 2b). The Himalayas also seem to have some downstream influence on the PAC EOF-1.

We analyze next the evolution of the $Z_{700}$ geopotential fields during the 20-30-day cycle in the Himalayas torque to interpret these relationships. The composites in Fig. 7 use a threshold value for the 20-30-day Himalayas torque of $12 \mathrm{H}$. This value ensures again that $N_{c}$ $=80$ maps are selected.

At -6 day lag (Fig. 7a), the circulation is anticyclonic almost everywhere with significant negative zonal wind anomalies in the subtropical central Pacific and a weak midlatitude jet over the North Atlantic sector. At -3 day lag, a positive Himalayas torque starts to build up, and the composite anomaly is dominated by an eastwest dipole pattern whose $\mathrm{N}-\mathrm{S}$ axis lies along the western flank of the Tibetan Plateau (Fig. 7b). At that time the negative zonal wind anomalies over the subtropical Pacific have significantly decreased compared to Fig. 7a. In phase with the Himalayas torque (Fig. 7c), the anomalies essentially present the dipole pattern along the western flank of the Tibetan Plateau that is responsible for the strong Himalayas torque in Fig. 2b. Elsewhere the circulation anomalies are rather weak, although a large-scale cyclonic monopole starts to cover 

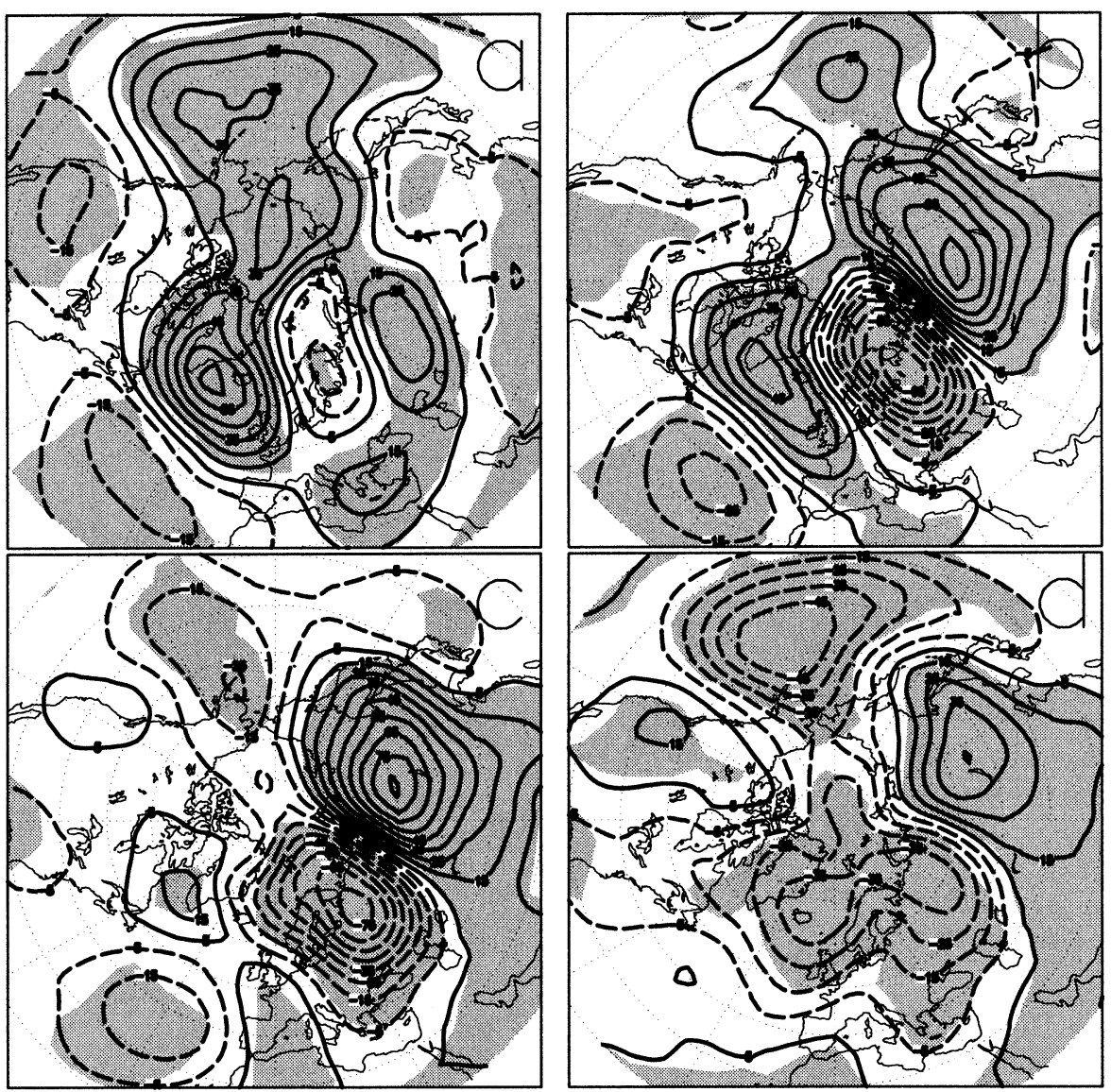

FIG. 7. Composite anomalies of $Z_{700}$ maps from the IS time series, keyed to the 20-30-day Himalayas mountain torque: (a) -6 day lag, (b) -3 day lag, (c) 0-day lag, and (d) 3-day lag. Same procedure, conventions and parameters as in Fig. 5 of Part I.

the Pacific basin, consistent with the downstream propagation found by Weickmann et al. (2000).

At 3-day lag (Fig. 7d) the cyclonic part of the eastwest dipole spreads westward and expands so that the

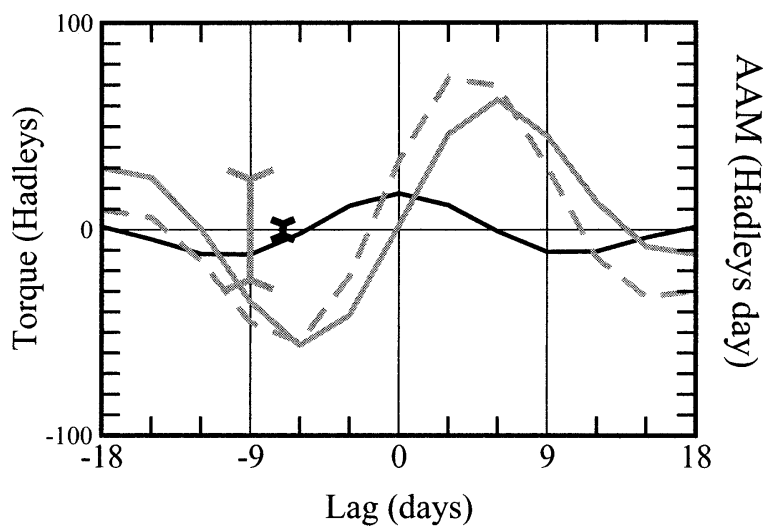

FIG. 8. Composites of different terms in the AAM budget during the composite cycle illustrated in Figs. 7: IS Himalayas torque (black solid), integral of IS Himalayas torque (gray solid), and global IS $M$ (gray dashed). Same conventions and parameters as in Fig. 6 of Part I. circulation becomes predominantly cyclonic over all of northern Europe. A cyclonic monopole now covers the Pacific basin where it is associated with enhanced subtropical zonal winds. At 6-day lag (not shown but the map is very similar to Fig. 7a with the sign reversed), the cyclonic anomaly that covers the Pacific basin is almost unchanged, while the cyclonic monopole that covers northern Europe in Fig. 7d splits into two cyclonic monopoles, one centered slightly east of Greenland and the other over western Siberia.

The composite evolution of the AAM budget in the IS band, as keyed to the evolution of the 20-30-day Himalayas torque, is plotted in Fig. 8. The AAM itself (dashed gray) exhibits even more substantial and significant variations than over the 20-30-day cycle in Rockies torque (Fig. 6). Furthermore, large and positive values of the AAM at +3 day and +6 day lag in Fig. 8 correspond to an enhanced subtropical jet over the central Pacific and an enhanced midlatitude Atlantic jet (see Fig. 7d but also Fig. 7a with the sign reversed). The composite of the Himalayas torque (black solid in Fig. 8) exhibits substantial and significant values as 
well. Its integral in time (gray solid) closely follows the composite evolution of the AAM.

The results in Fig. 8 are consistent with a substantial role for the Himalayas torque in affecting the flow patterns over the subtropical Pacific and over the northern Atlantic that appear in Fig. 7. We have verified quantitatively this point by looking at the contribution of these two sectors to the global AAM in the IS band. AAM composites of either sector (not shown) are almost in phase with and substantially smaller than the global AAM composites in Fig. 8. This result again remains valid if the sectorial contributions to $M$ are evaluated directly from the $Z_{700}$ composite maps using the geostrophic and hydrostatic balances. The Himalayas torque can thus easily account for the corresponding changes in both sectors.

The composites patterns over the Euro-Atlantic sector in Fig. 7 are strongly reminiscent of the NAO cycles that have been found in previous studies, near the frequency band of interest here. Over the North Atlantic and Europe, the maps in Figs. 7a-d match well the composite maps in Figs. 10a-d of Plaut and Vautard (1994), with the sign reversed; the latter describe half a cycle of the 30-35-day oscillation that dominates NAO variability from time to time. This oscillation is characterized by the retrogression of a dipole pattern from northeastern Europe toward the North Atlantic, as seen in our Figs. $7 \mathrm{c}$ and $7 \mathrm{~d}$.

\section{Mountain torques and winter circulation regimes}

LFV is often better described in terms of persistent flow patterns that have no preferred duration and whose onset and decay can be quite abrupt (Ghil 1987; Ghil and Robertson 2002; Koo et al. 2002). The oscillatory description in Part I and in sections 2, 3, and 4 above may underestimate, therefore, the relationships between mountain torques and LFV. This can be the case if the different series are only related episodically.

To establish statistically if such episodic links can be recognized, we next proceed with a regime classification based on the centroids of the Pacific and Atlantic sectorial regimes identified by Smyth et al. (1999), using a Gaussian mixture model. Their two Atlantic regimes resemble contrasting phases of the NAO pattern; hence we take the positive polarity of ATL EOF-2 in Fig. 3a as the first ATL regime centroid, and its negative polarity as the second one. These two regimes thus correspond to high and low NAO index, respectively (Hurrel 1995). The two Pacific regimes of Smyth et al. (1999) resemble contrasting phases of the PNP pattern, and hence of our PAC EOF-3 (Fig. 3b); thus we take PAC EOF-3 as the first PAC regime centroid, and minus PAC EOF-3 as the second one. Our two PAC regimes thus correspond to high- and low-index flow over this ocean basin (Namias 1950).

As in Mo and Ghil $(1987,1988)$ and Kimoto and Ghil (1993b), we use pattern correlation as the measure of distance between a given map and a regime centroid. We identify regime episodes as the individual 3-day mean maps whose pattern correlation with the corresponding centroid is greater than a given threshold; the date of the episode is the middle one of the 3 days over which the map is computed. We identify regime events to be the episodes that persist 6 days or longer without interuption. The onset of a given event is then taken as its first day and its break as its last day. For the $40 \mathrm{yr}$ of our dataset, we have chosen a pattern correlation threshold of 0.75 ; with this value, 50 to 70 episodes and 20 to 30 events are obtained for each of the four regimes described above.

To establish relationships between mountain torques and weather regimes, we first computed, for each mountain torque $T_{M}$ and for each weather regime episode $E$, the probability that $T_{M}$ is positive at a time $t$ counted from the date of $E$ :

$$
P\left(T_{M}>0 \text { at } t \text { after } E\right) .
$$

In all cases, and except when specified, the torque $T_{M}$ in Eq. (1) was taken from the IS (10-150 day) series of torques: NH, Rockies, or Himalayas.

\section{a. Atlantic regimes and mountain torques}

For the Atlantic sector, the probabilities of Eq. (1) show that Atlantic regime-1 episodes have a reduced probability (35\% at 3-day lag) to be followed by a positive NH torque, while regime-2 episodes have an enhanced probability (near $75 \%$ at 3-day lag) to be followed by a positive NH torque. To synthesize these findings and further test their statistical significance, we next combined them and evaluated the probability $P_{\text {ATL }}$ for NH mountain torque $T_{M}$ with respect to ATL regimes:

$$
\begin{array}{r}
P_{\text {ATL }}=P\left(\left\{T_{M}>0 \text { at } t \text { after } E_{1}\right\}\right. \text { or } \\
\left.\left\{T_{M}<0 \text { at } t \text { after } E_{2}\right\}\right) .
\end{array}
$$

The results that are significant at the $99 \%$ level are displayed in the Table 1; the statistical significance is estimated using a Monte Carlo procedure in which the computed probabilities are compared to an ensemble of probabilities computed with the same series and episodes but with randomly chosen lag. This test typically establishes that probabilities between $40 \%$ and $60 \%$ are not significant. These two values bracket $P_{\text {ATL }}=50 \%$, the expected result when the sign of the torque is entirely independent of the atmospheric circulation pattern and lag considered in Eq. (2).

The first row in Table 1 shows that there is significantly reduced probability that the $\mathrm{NH}$ mountain torque is positive 0,3 , and 6 days after episodes in regime 1 and negative after episodes in regime 2 . The second row reports the analysis results for the 20-30-day $T_{M}$ signal analyzed in sections 3 and 4 of Part I. It also shows 
TABLE 1. Probability (in percent) that a mountain torque $T_{M}$ (left column) is either positive $t$ days after an episode $E$ of ATL regime 1 or negative $t$ days after an episode $E$ of ATL regime 2. The IS stands for the intraseasonal 10-150-day band; 20-30-d stands for the series filtered by the 20-30-day bandpass filter displayed in Fig. 4b of Part I. Only values significant at the 99\% level are displayed. ( Roc $=$ Rockies and Him $=$ Himalayas $)$.

\begin{tabular}{lcccccc}
\hline \hline & \multicolumn{5}{c}{$t$ (days) } \\
\cline { 2 - 3 } \cline { 5 - 6 } & \multicolumn{2}{c}{$T_{M}$ leads } & & \multicolumn{3}{c}{$E$ leads } \\
\cline { 2 - 6 } & -6 & -3 & & 3 & 6 & 9 \\
\hline IS NH $T_{M}$ & & 33 & 30 & 34 \\
20-30-d NH $T_{M}$ & & 38 & 32 & 38 \\
IS Roc $T_{M}$ & & & & \\
20-30-d Roc $T_{M}$ & & 39 & 36 & 35 \\
IS Him $T_{M}$ & 61 & & 39 & 40 \\
20-30-d Him $T_{M}$ & & & & & \\
\hline
\end{tabular}

very significant probabilities at the same lags, indicating that the 20-30-day NH torque variations described in Part I are important in the episodic context as well. The third and fourth rows present the same statistics but using the intraseasonal Rockies and Himalayas torques, respectively. They show that only the Himalayas torque can be related to the ATL regime episodes at the $99 \%$ level, consistent with Fig. 7.

In ATL regime 1, $\mathrm{PC}-2$ is positive and the midlatitude jet intensity is larger than usual, while in regime $2, \mathrm{PC}-$ 2 is positive and the jet intensity is reduced. This finding, plus the fact that the probabilities in Table 1 are only significant at zero and small positive lag after regimes episodes, are consistent with the breaks of regime-1 events resulting, at least in part, from a brief deceleration of the westerly jet due to a negative $\mathrm{NH}$ mountain torque anomaly. Conversely, these results are also consistent with the breaks of regime- 2 events resulting, at least in part, from a brief acceleration due to a positive $\mathrm{NH}$ mountain torque anomaly.

Following this interpretation, we computed the probability that the NH mountain torque in the IS band is negative during the breaks of regime- 1 events and positive during the breaks of regime- 2 events. This probability is close to $80 \%$, and highly significant; it still equals $77 \%$ if one tests the sign of the $\mathrm{NH}$ mountain torque in this band 3 days after the regime event breaks. Testing the sign of the IS Himalayas torque results in a probability of $70 \%$ during the regime event breaks.

\section{b. Pacific regimes and mountain torques}

To check if mountain torques are related to the PAC regimes as well, we computed the probability that the mountain torque is positive after a Pacific regime episode. In more than $70 \%$ of cases, episodes in PAC regime 1 are preceded for a few days $(t=-6,-3$, and 0 day) by a positive torque. Conversely, in less than $35 \%$ of cases the episodes in PAC regime 2 are preceded for a few days ( $t=-6$ and -3 days) by a positive torque.
TABLE 2. Probability (in percent) that a mountain torque $T_{M}$ (left column) is either positive $t$ days after an episode $E$ of PAC regime 1 or negative $t$ days after an episode $E$ of PAC regime 2. Same conventions and parameters as in Table 1.

\begin{tabular}{|c|c|c|c|c|c|c|c|}
\hline & \multicolumn{7}{|c|}{$t$ (days) } \\
\hline & \multicolumn{3}{|c|}{$T_{M}$ leads } & \multirow[b]{2}{*}{0} & \multicolumn{3}{|c|}{$E$ leads } \\
\hline & -15 & -6 & -3 & & 3 & 6 & 9 \\
\hline IS NH $T_{M}$ & & 66 & 74 & 66 & & & 39 \\
\hline 20-30-d NH $T_{M}$ & & 65 & 71 & 61 & & 35 & 32 \\
\hline IS Roc $T_{M}$ & & 71 & 79 & 67 & & & \\
\hline $\begin{array}{l}\text { 20-30-d Roc } T_{M} \\
\text { IS Him } T_{M} \\
\text { 20-30-d Him } T_{M}\end{array}$ & 37 & 68 & 69 & 61 & & 37 & 37 \\
\hline
\end{tabular}

We evaluated again the combined probability $P_{\text {PAC }}$ of the two types of circumstances,

$$
\begin{array}{r}
P_{\mathrm{PAC}}=P\left(\left\{T_{M}>0 \text { at } t \text { after } E_{1}\right\}\right. \text { or } \\
\left.\left\{T_{M}<0 \text { at } t \text { after } E_{2}\right\}\right) .
\end{array}
$$

The most highly significant results are shown in Table 2. Row 1 indicates that a strong IS signal in NH mountain torque precedes the Pacific regime episodes at 3, 6 , and 9 days. Row 2 confirms that this lead-lag relationship in the IS band largely results from the 20-30day signal described in Part I. In this narrower band a very significant $\mathrm{NH} T_{M}$ signal is present even 15 days prior to the PAC regime episodes. The last two rows in Table 2 show that the above results are not much modified if one considers the Rockies torque only. This finding and the results in Fig. 5 are consistent with the Rockies torque having an upstream influence on the PAC regimes.

That the mountain torque changes precede the PAC regime episodes suggests that the former can be related to the onset of PAC regime events. To address this point we next computed the probability that the mountain torque is positive at the onset of events in PAC regime 1 and negative at the onset of events in PAC regime 2. When computed for the NH torque in the IS band, this probability is close to $84 \%$. If the torque value is taken 3 days prior to a PAC regime onset, the probability of the torque having the appropriate sign is still $80 \%$. Again, these links result primarily from an upstream influence of the Rockies, as the two probabilities above are $69 \%$ and $77 \%$ when evaluated using the Rockies torque in this band.

\section{Concluding remarks}

The NH mountain torque variations described in Part I of this study (Lott et al. 2003) are often associated, in the 20-30-day band, with highly regional circulation patterns (see Fig. 2 of Part I and Figs. 2a,b here). Moreover, the contribution of the Rockies and Himalayas to the NH mountain torque $T_{M}$, while jointly making up $85 \%$ of the variance in the latter, are largely independent 
of each other (see Fig. 1 here and its discussion in section 2a). These two facts motivate our regional analysis in the present Part II.

This analysis used three partially overlapping sectors which we dubbed ATL $\left(90^{\circ} \mathrm{W}-90^{\circ} \mathrm{E}\right)$, ASI $\left(0^{\circ}-180^{\circ}\right)$, and PAC $\left(120^{\circ} \mathrm{E}-60^{\circ} \mathrm{W}\right)$. A spectral analysis of the relationships between regional mountain torques and the dominant patterns of sectorial LFV identified clear signals in the 20-30-day band (Fig. 4). These dominant patterns were obtained by principal component (PC) analysis of year-round low-frequency variability (LFV).

At small lag, the Rockies torque is significantly related to PAC EOF-3 variability and the Himalayas torque is related to EOFs 2 and 3 of ASI LFV. These three regional LFV patterns are naturally associated with a mountain torque because they are strongly nonzonal and centered upstream of the Rockies, for PAC EOF3, and the Tibetan Plateau, for the Asian EOFs 2 and 3 . When the atmospheric circulation locally resembles one of these patterns, the associated zonal pressure gradients across the corresponding mountain range are large and result in a substantial torque. These patterns exhibit, therefore, lag relationships of near simultaneity with the appropriate regional mountain torque; the torque tends, nevertheless, to lead PAC PC-3 by a few days (see Fig. 4 and its discussion in section $3 \mathrm{a}$ ).

As in our hemispheric analysis (Part I), there are also dominant regional LFV patterns that do not exhibit substantial pressure gradients across the major mountain ranges. These patterns include all three first-ranked regional EOFs, as well as the second-ranked EOFs, that is, the West Pacific Oscillation and the NAO in our analysis. Each of these patterns is predominantly zonal in character and thus does not give rise to a mountain torque, in and of itself. The torques lead these zonal patterns by nearly one-quarter period in the 20-30-day band, consistent with the former driving the changes in the latter.

The atmospheric flow field composites that accompany the 20-30-day mountain torques allow us to understand these relationships. Over the northeastern Pacific and North America, as well as the northeastern Atlantic and Europe, these composites resemble the atmospheric oscillations that dominate NH LFV from time to time, as found in previous studies (Branstator 1987; Kushnir 1987; Ghil and Mo 1991; Plaut and Vautard 1994). During these oscillations, and apparently in response to the regional torques (the Rockies torque for Fig. 5 and the Himalayas torque for Fig. 7) substantial AAM changes do occur in the IS (10-150 day) band. For the Rockies torque, these AAM changes can be attributed directly to the flow patterns in the midlatitude eastern Pacific (see Fig. 5).

Accordingly, the results in Fig. 5 are consistent with the Rockies torque driving, to a substantial degree, the changes in the midlatitude jet seen in these maps. The same analysis for the Himalayas torque suggests that the latter can partly drive the changes in the subtropical
Pacific and in the midlatitude North Atlantic seen in the composite maps of Fig. 7.

We have also investigated systematically to what extent the regional results here are related to the hemispheric ones in Part I. We found, for instance, that the Himalayas and the Rockies torque are both linked with the NH EOF-1. The Himalayas contribution is nevertheless larger than that of the Rockies. The Himalayas $T_{M}$ also leads the NH EOF-2, by about a quarter of a period, but we found no significant link between the Rockies torque and NH EOF-2.

Conversely, we found highly significant links between the hemispheric $T_{M}$ and the regional EOFs (not shown). These links imply that the changes in the $\mathrm{NH}$ $T_{M}$ are related to substantial circulation anomalies in all three sectors. The most striking relationship is between the hemispheric torque and PAC PC-3; the links between the Rockies torque and PAC PC-3 presented in section $3 \mathrm{a}$ here are at the basis of this relationship. Likewise, we find links between the $\mathrm{NH}$ mountain torque (not shown) and ATL PC-2, based on the relationship between the Himalayas torque and ATL PC-2, mentioned in section $4 \mathrm{a}$.

It is also instructive to compare the composite maps in Figs. 5 and 7 with the composite maps in Fig. 5 of Part I. Doing so shows that the atmospheric flow field variations associated with the 20-30-day $\mathrm{NH} T_{M}$ (see Fig. 5 of Part I) are essentially associated with the Himalayas torque: except near the Rockies, the composite maps in Fig. 5 of Part I are very similar to those associated with the Himalayas torque in Fig. 7 here.

This comparison also helps to interpret the westward development of the large-scale cyclonic anomaly that covers the whole Pacific basin, in near quadrature with the 20-30-day NH torque (Figs. 5b and 5c in Part I). When the two regional torques vary in phase to give a significant 20-30-day $\mathrm{NH} T_{M}$, the patterns associated with each of them in Figs. 5 and 7 here reinforce each other. The cyclonic pattern lying to the west of the Rockies at 0-day lag in Fig. 5a of Part I corresponds to that associated with the Rockies torque at the same lag (Fig. $5 \mathrm{~b}$ here). The strong extension toward the west of this pattern 3 days later (Fig. 5b of Part I) results from the fact that the cyclonic pattern associated with the Rockies torque has spread toward the northwest at that time (Fig. $5 \mathrm{c}$ here) and from the fact that the Himalayas torque is also associated with a large-scale cyclonic pattern over the central North Pacific at the same time (Fig. 7d here).

Complementing this description of sectorial LFV, we also carried out an investigation of sectorial regimes. To do so, we relied on the previous work of Smyth et al. (1999) and chose our regimes centroids to coincide with theirs, which in turn resemble those of Cheng and Wallace (1993; see also Ghil and Roberstson 2002). These centroids correspond essentially to opposite polarities of the NAO and PNP patterns, in the Atlantic and the Pacific sector, respectively. Our regimes thus represent the persistent, quasi-stationary flow configu- 
rations that characterize, from time to time, the largescale flow in the midlatitudes.

We found a significant signal in the intraseasonal $\mathrm{NH}$ mountain torque during the breaks of the two Atlantic regimes that resemble opposite phases of the NAO: a negative torque at the end of the zonal-flow events and a positive torque at the end of the blocked-flow events. This effect is primarily due to the Himalayas torque (see Table 1). As blocked-flow events are associated with reduced jet intensity, we found here that a process that tends to augment AAM can help end blocking. Conversely, it is not surprising to find that a process that tends to reduce AAM can help end a zonal-flow event, characterized by an intense jet.

We found, moreover, a signal in the $\mathrm{NH}$ mountain torque during the onset of the two PAC regimes: a positive one at the beginning of zonal-flow events and a negative torque at the beginning of blocked-flow events. This precursor signal is primarily due to the Rockies torque (see Table 2). Again, as the Rockies torque enhances AAM, it is not surprising to find a positive torque preceding zonal-flow events and a negative torque preceding blocked-flow events, which are associated with a strong as opposed to a weak jet over the eastern $\mathrm{Pa}$ cific.

To determine if the 20-30-day mountain torques are in part responsible for the above transitions, we repeated the statistical estimates of Tables 1 and 2 using the 2030-day mountain torque signals constructed with the 20-30-day bandpass filter used in Part I. The relationships between mountain torques and flow regimes in this band (see again Tables 1 and 2) are consistent with a significant participation of the 20-30-day signals in the flow regime transitions. The predictive value of these lead-lag relationships between mountain torques and large-scale sectorial flow patterns, if any (Lott et al. 2001; Ghil and Robertson 2002; Koo et al. 2002), remains to be evaluated.

The results presented here are consistent with the mountain torques playing an active role in NH LFV. Some of the observed relationships between torques and LFV patterns found in Parts I and II could, however, result from processes in which the mountains do not play a crucial role. This might be the case when nontopographic traveling Rossby waves driven by other processes pass over major mountain ranges. Further modeling and observational studies will help, no doubt, determine the exact role of topography in atmospheric LFV.

Acknowledgments. The authors are grateful to past and present associates on three continents for interesting exchanges on low-frequency atmospheric variability. The NCEP-NCAR reanalysis data are provided through the NOAA Climate Diagnostics Center (http:// www.edc.noaa.gov). Extensive and persistent comments by Klaus M. Weickmann and two anonymous referees have greatly improved the presentation of our results.
Our work was supported by NASA Grant NAG5-9294 (FL), DOE Grant DE-FG03-01ER63260 (AWR), and NSF Grant ATM-0082131 (MG). This is publication 5837 of UCLA's Institute of Geophysics and Planetary Physics.

\section{REFERENCES}

Barnston, A. G., and R. E. Livezey, 1987: Classification, seasonality and persistence of low-frequency atmospheric circulation patterns. Mon. Wea. Rev., 115, 1083-1126.

Branstator, G., 1987: A striking example of the atmosphere's leading traveling pattern. J. Atmos. Sci., 44, 2310-2323.

Cheng, X., and J. M. Wallace, 1993: Cluster analysis of the Northern Hemisphere wintertime 500-hPa height field: Spatial patterns. $J$. Atmos. Sci., 50, 2674-2696.

Dickey, J. O., M. Ghil, and S. L. Marcus, 1991: Extratropical aspects of the 40-50 day oscillation in length-of-day and atmospheric angular momentum. J. Geophys. Res., 96, 22 643-22 658.

Dole, R. M., and N. M. Gordon, 1983: Persistent anomalies of the extratropical Northern Hemisphere wintertime circulation: Geographical distribution and regional persistence characteristics. Mon. Wea. Rev., 111, 1567-1586.

, and R. X. Black, 1990: Life cycles of persistent anomalies. Part II: The development of persistent negative height anomalies over the North Pacific Ocean. Mon. Wea. Rev., 118, 824-846.

Ghil, M., 1987: Dynamics, statistics and predictability of planetary flow regimes. Irreversible Phenomena and Dynamical Systems Analysis in the Geosciences, C. Nicolis and G. Nicolis, Eds., D. Reidel, 241-283.

_ , and K.-C. Mo, 1991: Intraseasonal oscillations in the global atmosphere. Part I: Northern Hemisphere and tropics. J. Atmos. Sci., 48, 752-779.

- , and A. W. Robertson, 2002: Waves vs. particles in the atmosphere's phase space: A pathway to long-range forecasting? Proc. Natl. Acad. Sci., 99 (Suppl. 1), 2493-2500.

_- M. Kimoto, and J. D. Neelin, 1991a: Nonlinear dynamics and predictability in the atmospheric sciences. Rev. Geophys., 29 (Suppl.), 46-55.

—, S. L. Marcus, J. O. Dickey, and C. L. Keppenne, 1991b: AAM the Movie. NTSC Videocassette AVC-91-063, Caltech/NASA Jet Propulsion Laboratory, Pasadena, CA.

Hurrell, J. W., 1995: Decadal trends in the North Atlantic Oscillation regional temperatures and precipitation. Science, 269, 676-679.

Kalnay-Rivas, E., and L. O. Merkine, 1981: A simple mechanism for blocking. J. Atmos. Sci., 38, 2077-2091.

Kimoto, M., and M. Ghil, 1993a: Multiple flow regimes in the Northern Hemisphere winter. Part I: Methodology and hemispheric regimes. J. Atmos. Sci., 50, 2625-2643.

$\ldots$, and _ $1993 \mathrm{~b}$ : Multiple flow regimes in the Northern Hemisphere winter. Part II: Sectorial regimes and preferred transitions. J. Atmos. Sci., 50, 2645-2673.

Koo, S., A. W. Robertson, and M. Ghil, 2002: Multiple regimes and low-frequency oscillations in the Southern Hemisphere's zonalmean flow. J. Geophys. Res., 107, 4596, doi:10.1029/ 2001JD001353.

Kushnir, Y., 1987: Retrograding wintertime low-frequency disturbances over the North Pacific Ocean. J. Atmos. Sci., 44, 2727 2742.

Lott, F., A. W. Robertson, and M. Ghil, 2001: Mountain torques and atmospheric oscillations. Geophys. Res. Lett., 28, 1207-1210.

$\ldots, \ldots$, and _ $\_$2004: Mountain torques and Northern Hemisphere low-frequency variability. Part I: Hemispheric aspects. $J$. Atmos. Sci., 61, 1259-1271.

Marcus, S. L., M. Ghil, and J. O. Dickey, 1996: The extratropical 40-day oscillation in the UCLA general circulation model. Part II: Spatial structure. J. Atmos. Sci., 53, 1993-2014.

Mo, K., and M. Ghil, 1987: Statistics and dynamics of persistent anomalies. J. Atmos. Sci., 44, 877-901. 
, and — - 1988: Cluster analysis of multiple planetary flow regimes. J. Geophys. Res., 93D, $10927-10952$.

Molteni, F., S. Tibaldi, and T. Palmer, 1990: Regimes in the wintertime circulation over northern extratropics. Part I: Observational evidence. J. Atmos. Sci., 47, 31-67.

Namias, J., 1950: The index cycle and its role in the general circulation. J. Meteor., 7, 130-139.

Penland, C., M. Ghil, and K. M. Weickmann, 1991: Adaptive filtering and maximum entropy spectra with application to changes in atmospheric angular momentum. J. Geophys. Res., 96, 22 65922671.

Plaut, G., and R. Vautard, 1994: Spells of low-frequency oscillations and weather regimes in the Northern Hemisphere. J. Atmos. Sci. 51, 210-236.
Smyth, P., K. Ide, and M. Ghil, 1999: Multiple regimes in Northern Hemisphere height fields via mixture model clustering. J. Atmos. Sci., 56, 3704-3723.

Van Loon, H., and J. C. Rogers, 1978: The seesaw in winter temperature between Greenland and northern Europe. Part I: General description. Mon. Wea. Rev., 106, 296-310.

Vautard, R., K. C. Mo, and M. Ghil, 1990: Statistical significance test for transition matrices of atmospheric Markov chains. J. Atmos. Sci., 47, 1926-1931.

Wallace, J. M., and D. S. Gutzler, 1981: Teleconnections in the geopotential height field during the Northern Hemisphere winter. Mon. Wea. Rev., 109, 784-812.

Weickmann, K. M., W. A. Robinson, and C. Penland, 2000: Stochastic and oscillatory forcing of global atmospheric angular momentum. J. Geophys. Res., 105 (D12), 15 543-15 557. 